\title{
O educador musical na educação especial: a trajetória de três professores
}

Vinicius Nicolodelli

Recebido em 02/06/2018

Aprovado em 06/10/2018 
Esta pesquisa tem por meta conhecer e analisar a formação de professores de música que atuam com a educação especial. Neste sentido, busca compreender a formação do educador, sua experiência e os desafios encontrados no dia a dia. Revisando a literatura foi possível encontrar cinco pesquisas acadêmicas (ALMEIDA, 2004; SOARES, 2006; SANTOS, 2008; MACHADO, 2012; e VIANA, 2015) que tem como temática a formação de professores de música que atuam com a Educação Musical Especial e com o Ensino Inclusivo. Para que a pesquisa fosse possível, os dados foram coletados por meio de entrevistas online com três educadores musicais que atuaram ou ainda atuam no contexto da educação musical especial. Os resultados indicam que a formação destes professores esteve atrelada à atuação durante suas trajetórias e que, apesar das barreiras encontradas, superaram desafios buscando conhecimentos que pudessem auxiliá-los em suas práticas educacionais.

Palavras-chave: Formação de professores. Educação Musical Especial. Trajetória acadêmica.

\section{INTRODUÇÃO}

A discussão acerca do ensino inclusivo se faz presente em diferentes níveis de ensino. Leis como a 9.394/96 garantem o direito do aluno com deficiência à inclusão escolar (BRASIL, 1996). Sendo que, a cada dia, mais alunos com necessidades especiais estão inseridos nas salas de aulas de ensino regular, o educador musical tem papel fundamental como facilitador do conhecimento. Sendo assim, este deve estar preparado para lidar com as especificidades dos alunos na sala de aula para que, assim, o ensino inclusivo seja de fato realidade. Porém, qual é a formação de professores de música que atuam em contexto de Educação Inclusiva e Educação Especial? Quais os conhecimentos musicais e específicos do campo da Educação Especial eles detêm? Onde os adquiriram? Como? Diante destas questões desenvolvi um estudo com três educadores musicais que já atuaram ou ainda atuam nos contextos acima 
citados. Para que estas perguntas fossem sanadas, realizei entrevistas semi-estruturadas buscando compreender como ocorreu a formação dele e de que maneira atuam.

Este texto está organizado da seguinte maneira: primeiramente trago a revisão de literatura, dando mais profundidade às pesquisas acadêmicas acima citadas para uma contextualização sobre o tema. Seguindo, trago a metodologia utilizada para esta pesquisa; nela apresento o perfil dos entrevistados. Posteriormente, descrevo a trajetória de formação e atuação dos participantes, para assim no último item trazer as conclusões resultantes desta pesquisa.

\section{O QUE DIZEM AS PESQUISAS?}

Ao pesquisar na Biblioteca Digital de Teses e Dissertações (BDTD), no Banco de Teses da CAPES, e em bancos de pesquisas acadêmicas como o Google Acadêmico, foi possível encontrar cinco pesquisas acadêmicas que trazem como foco a formação do professor de música para a Educação Musical Especial, estas pesquisas têm em comum o intuito de contribuir para que a inclusão de alunos com deficiência nas salas de aulas de ensino regular aconteça de fato. Sobre estas pesquisas então destaco: Almeida (2004), Soares (2006), Santos (2008), Machado (2012) e Viana (2015). Para Santos (2008) o tema Educação Musical Especial é algo que está despertando o interesse de alguns pesquisadores há pouquíssimo tempo e, para justificar essa afirmação, a autora recorre então à Fernandes (2000, 2006 e 2007) ao dizer que a maioria dos trabalhos acadêmicos no campo da Educação Musical estavam focados apenas no processo de ensino-aprendizagem. A autora ainda diz que a escassez de pesquisas acontecia pela falta de preparo de professores para lidar com alunos deficiente nas aulas de música e pela falta de especializações que compreendam a Educação Musical Especial. A falta de preparo se deve pois, durante a graduação, apenas o estágio, algumas vezes, e uma ou outra disciplina trata sobre este tema.

Soares (2006) alerta que é importante que cursos de licenciatura em música "favoreçam a reflexão sobre a inclusão, tendência segundo a qual a sociedade deve reorganizar-se para 
atender todas as pessoas sem discriminações ou rotulações, valorizando as diferenças, sejam elas quais forem." (p.5). Ainda segundo a autora, muitos julgam não estarem preparados para atender alunos com necessidade especiais em sala de aula. Para que isso seja revertido faz-se necessário que o professor, não só de música, mas qualquer professor que esteja no contexto da educação especial, tome importantes cuidados diante de alunos com necessidades especiais.

Machado (2012), teve em sua pesquisa a meta de investigar como os professores de música atuantes na rede pública de ensino básico da cidade de Florianópolis lidam com alunos com deficiência em suas aulas. Em busca de compreender como este processo acontece, a autora teve como intuito analisar aspectos da inclusão destes alunos na aula de música e compreender quais os conhecimentos que os professores têm sobre a Educação Especial, tanto o conhecimento obtido durante a graduação quanto em cursos de formação continuada. Utilizando o survey como método de pesquisa, com o intuito de atingir um maior número de participantes, Machado (2012) aplicou um questionário a um grupo de professores de música. Com estes dados a autora chega à que os mesmos sentem-se despreparados e têm dificuldade em lidar com alunos de inclusão.

Viana (2015) além de discutir sobre a importância dessa formação para os professores, propôs em sua pesquisa um curso de capacitação na UFSCar para alunos licenciandos do curso de música e professores da rede básica de ensino de São Carlos. A autora procurou discutir com os participantes conhecimentos relativos ao ensino de música para alunos com deficiência intelectual e auditiva. Entretanto, os resultados coincidem com os de Machado (2012), pois segundo a análise de Viana (2015) os resultados indicaram que professores de música alegam não estar preparados para lidar com alunos com necessidades especiais.

Baseando-se nas pesquisas acimas citadas fica claro a necessidade da discussão acerca da formação dos professores para com a educação musical especial. Analisar como se deu a formação de professores que já atuaram com o ensino de música na educação especial talvez possa clarear o debate sobre o tema. 


\section{METODOLOGIA}

Esta pesquisa foi desenvolvida a partir da abordagem qualitativa, a partir de um estudo exploratório . A técnica utilizada para essa coleta foi a entrevista realizada por meio de recursos online, ou seja, foram realizadas via chats e videoconferências, usando o Skype ${ }^{1}$, WhatsApp ${ }^{2}$ e Facebook ${ }^{3}$.

Para este estudo, organizei um roteiro de entrevistas em eixo distintos e complementares: formação do professor; sobre a atuação; sobre o campo da Educação Musical em relação a Educação Especial; e sobre o campo da Educação Musical Especial. Construir este roteiro consistiu em criar uma linha do tempo da vida acadêmica e profissional do entrevistado. Para que assim tivesse um início (o primeiro contato com a música), um meio (vida acadêmica e profissional), chegando no atual momento de suas vidas (os resultados de suas experiências até o momento). Segundo Stake (2011), planejar um instrumento de coleta de dados é uma grande tarefa. Um dos propósitos para o uso das entrevistas é "obter informações singulares ou interpretações sustentadas pela pessoa entrevistada" (p.108).

As entrevistas foram gravadas e posteriormente transcritas, catalogadas para que assim os dados obtidos pudessem analisados com base nas referências trazidas e seguindo os princípios da abordagem qualitativa. Os participantes desta pesquisa atendem aos seguintes critérios: o tempo de atuação (mais de 7 anos no campo), experiências diferentes na atuação com alunos especiais, professores pesquisadores sobre temas como inclusão e Educação Musical Especial. Apresento no quadro a seguir os professores, que consentiram na publicação de seus nomes, que contribuíram para esta pesquisa (Quadro 1):

\footnotetext{
1 Rede social que possibilita a troca de mensagens, assim como ligações e vídeochamadas.

${ }^{2}$ Aplicativo de celular de troca de mensagens, ligações e vídeo-chamadas.

3 Rede Social onde pode-se encontrar o perfil de usuários cadastrados e suas informações, assim como possibilita a troca de mensagens.
} 


\begin{tabular}{|c|c|c|}
\hline NOME & FORMAÇÃo & $\begin{array}{c}\text { DEFICIENCIAS/DOENCAS COM } \\
\text { AS QUAIS TRABALHA OU JÁ } \\
\text { TRABALHOU }\end{array}$ \\
\hline Viviane Louro & $\begin{array}{c}\text { Bacharel em piano, } \\
\text { Mestrado em } \\
\text { Educação Musical } \\
\text { e Doutora em } \\
\text { Neurociências }\end{array}$ & $\begin{array}{c}\text { Pessoas com problemas } \\
\text { psiquiátricos e autismo }\end{array}$ \\
\hline Rafael Vanazzi & $\begin{array}{c}\text { Bacharel em } \\
\text { Composição, } \\
\text { Mestrado em } \\
\text { Educação Musical }\end{array}$ & $\begin{array}{c}\text { Cegueira } \\
\text { Lisbeth Soares }\end{array}$ \\
$\begin{array}{c}\text { Pedagogia com } \\
\text { enfase em Educação } \\
\text { Especial, técnica } \\
\text { em música, } \\
\text { Mestrado em } \\
\text { Educação Especial } \\
\text { e doutoranda em } \\
\text { Educação }\end{array}$ & $\begin{array}{c}\text { Deficiência intelectual, } \\
\text { deficiência física, TEA., } \\
\text { atrasos no desenvolvimento } \\
\text { Neuropsicomotor. }\end{array}$ \\
\hline
\end{tabular}

Quadro 1. Breve perfil dos professores entrevistados

Por meio do Facebook contatei a professora Viviane, depois marquei vídeo-chamada via Skype em um horário que ficasse bom para ambos. Já os professores Rafael e Lisbeth entrei em contato por e-mail e então marcamos uma conversa por WhatsApp, depois combinei com cada um horário acessível para realizarmos vídeo-chamada via Skype.

\section{QUEM SÃO OS EDUCADORES ENTREVISTADOS?}

\section{Viviane}

Professora Viviane teve sua formação inicial no piano erudito. Fez bacharelado em piano, mas foi no mestrado que começou a se interessar pela pesquisa e pela educação musical. Nele, ela fez sua pesquisa voltada para a área da inclusão, foi então que, segundo ela, percebeu a defasagem em estudos relacionados ao tema e começou a se interessar cada vez mais pelos estudos 
nesta área. Durante o seu mestrado, um colega a chamou para dar aula para pessoas com problemas psiquiátricos em uma ONG em São Paulo. De início encontrou dificuldades pois ainda não tinha muito conhecimento sobre o assunto. Embora ela tivesse aceitado o convite, a professora relatou que não sabia como atuar nesta área e entrou "em desespero" porque "não tinha ideia do que fazer".

O estar "em desespero" foi o fator mobilizador para que ela buscasse conhecimentos na área. Isso a fez ir visitar outros campos, levando-a a fazer cursos em áreas como da psicologia, psiquiatria, neurologia, medicina. Toda as oportunidades de fazer cursos, que julgava ajudar, ela fazia: "A APAE ${ }^{4}$, por exemplo, dá muitos cursos pra professores, então todos esses lugares que davam curso eu fazia". No total afirma ter cerca de duas mil horas em cursos.

Nesses cursos ela começou a estudar o ser humano e a compreender e a saber lidar com pessoas com necessidades especiais. Por já ter conhecimentos musicais, começou então a relacionar os conhecimentos adquiridos com a música.

Os cursos feitos sobre as patologias a ajudaram entender melhor seus alunos. Juntando estes conhecimentos com os musicais é possível descobrir e desenvolver uma prática própria para que o ensino-aprendizagem de música para pessoas com necessidades especiais se faça presente. Afinal, a atuação no campo da educação musical é complexo e depende outras disciplinas, outras áreas (KRAEMER, 2000).

\section{Rafael}

Já Rafael teve seu primeiro contato com a música no conservatório de Barra Mansa - Rio de Janeiro, sua cidade natal. Lá cursou piano, teoria musical, harmonia e prática coral, requisito obrigatório do curso. Estudou dos sete aos dezoito anos de idade e logo depois já começou a dar aulas em uma escola de música de Volta Redonda - RJ. Após entrou no bacharelado em composição na UNICAMP.

Regeu corais, substituindo maestros, fez curso de regência coral, também na UNICAMP, e também cursos de regência coral. 
Em 2006, surgiu a oportunidade de reger um coral de cegos em Campinas. E foi da necessidade que veio o interesse de pesquisar o que fazer e como ensinar música para cegos.

Contudo, ele não fez nenhum curso para atuar neste campo. Ele se debruçou sobre os materiais que teve acesso e começou a estudar de acordo com as demandas que foram surgindo. Na sequência, começou a ministrar cursos de formação de partitura em Braile, e na prática, ele começou a entender melhor como ensinar, criar exercícios e a vencer as primeiras dificuldades.

A sala de aula foi um verdadeiro curso de aprendizagem para o próprio Rafael. Ele contou que sentia muita dificuldade no começo pois não tinha ninguém para auxiliá-lo. Contudo, foi na prática, nos detalhes que alunos percebiam, que por algumas vezes ele não tivesse percebido, que fez com que a cada dia sua didática fosse se desenvolvendo e o fio condutor de seu processo de ensino fosse se consolidando. $\mathrm{E}$, em sala de aula que ele foi aprendendo a dar aulas.

\section{Lisbeth}

Diferentemente dos outros entrevistados, Lisbeth teve sua formação musical com curso técnico de música. Seu ensino médio foi juntamente com o magistério e depois entrou para a faculdade de Pedagogia com ênfase em Educação Especial. O interesse por essa área veio ainda no magistério quando aceitou o convite de uma professora para auxiliá-la na sala de recursos ${ }^{5}$ da escola. Isso a despertou para a área de modo que quando se inscreveu no vestibular, optou pela habilitação em Educação Especial.

Segundo a professora, a Educação Musical aconteceu "naturalmente e sem intensão". Como estudou música desde criança buscava, por vezes, uma maneira de trazê-la às suas aulas. Na necessidade de um professor de música substituto na escola em que estudou assumiu então o cargo oficialmente. No ano de 2004, Lisbeth entrou para o Mestrado na UFSCAR com sua pesquisa voltada para a prática musical e a inclusão de pessoas com necessidades especiais. Entretanto, quando iniciou

5 Ao perguntar para a professora sobre o que seria esta sala ela me explicou que, com aulas no contraturno, o objetivo é utilizar instrumentos pedagógicos que facilitem o aprendizado do aluno com deficiência nas salas regulares. 
o mestrado já trabalhava como professora de Artes na Escola Especial e como professora de Música em escola específica, assim, o tema para a dissertação surgiu de sua prática profissional.

Como já atuou com a educação especial antes mesmo de entrar para a faculdade, buscou fazer com que a sua vida acadêmica fosse voltada para a Educação Especial. Com a fala da professora pude perceber que o interesse para com a área a levou a buscar a formação acadêmica necessária para que pudesse continuar atuando no campo.

É possível notar que há uma diferença de Lisbeth com os outros entrevistados quando falamos de formação acadêmica. No caso da professora, a Educação Especial e a sua formação sempre estiveram lado a lado desde o começo. Já no caso de Viviane e Rafael, eles descobriram o interesse pelo campo após as suas graduações. Tem aqui um ponto que julgo importante para reflexão. Se analisarmos o caso de Lisbeth vemos que a professora já estava ciente com que quais alunos poderia se deparar, devido a ênfase de sua graduação.

\section{A AUTOAPRENDIZAGEM DOS PROFESSORES}

Dou início a este tópico delimitando o conceito de autoaprendizagem:

[...] autoaprendizagem diz respeito a contextos não formais de aprendizagem, onde o aluno se coloca como aprendiz e tem liberdade total de decisão sobre sua aprendizagem. Ao trabalharmos no ensino formal, onde o aluno está inserido em uma proposta pedagógica que possui estrutura previamente definida, este não tem liberdade total sobre sua aprendizagem. (WESTERMANN, 2012, p.82)

A autoaprendizagem foi um ponto em comum na vida profissional de Viviane e Rafael. No relato deles notei que a falta de cursos profissionalizantes foi um obstáculo encontrado. Entretanto, mesmo assim procuravam ler tudo sobre o assunto mesmo que não fossem produções diretamente ligadas à Educação Musical, como foi o caso de Viviane, por exemplo, ao estudar temas como a neurociência e a psicomotricidade. 
No caso de ambos os entrevistados pode se dizer que a autoaprendizagem também se deu em suas próprias práticas em sala de aula. A medida com que lecionavam aprendiam cada vez mais, fosse como lidar com seus alunos ou a conciliar todos os conhecimentos obtidos para o auxílio da didática. O processo de autoaprendizagem nas vivências dos professores entrevistados foi fundamental para suas práticas em sala de aula. Ao analisar este ponto uma indagação permeou meus pensamentos: seria a autoaprendizagem a única saída para o processo de ensinoaprendizagem de pessoas com deficiência?

A autoaprendizagem é inevitável e natural no decorrer da prática dos professores, mas ela não deve ser o único recurso. Volto a bater na tecla de que o aumento do número de pesquisa científicas é de extrema importância para a construção de conhecimentos. Viviane, em um de seus relatos, afirma que conhece professores que estão em sala de aula no ensino regular, ensinando música, que têm alunos de inclusão, mas que muitos não sabem o que esse professor está ensinando, o que esse professor sabe sobre inclusão, o que acontece na sala.

Se as experiências e relatos no campo da Educação Musical Especial forem socializadas em pesquisas científicas, blogs, revistas, ou em meios de comunicação como a internet, a comunidade de pesquisa se beneficia cada vez mais com esses registros ao alcance de nossos olhos.

Mesmo a auto formação sendo de grande ajuda e auxiliando todos os entrevistados, a formação acadêmica também foi comum entre eles. Viviane, Rafael e Lisbeth encontraram no mestrado uma forma seja de se interessar mais ainda pelo tema da inclusão ou para contribuir para o campo da pesquisa com suas dissertações.

\section{A FORMAÇÃO APÓS A GRADUAÇÃO}

O mestrado foi um dos pontos mais destacado pelos entrevistados. No caso de Viviane, foi no mestrado em que se deparou com a falta de pesquisas relacionadas aos temas inclusão e ensino de música na educação especial. Segundo ela foi aí que o interesse pelos temas aflorou: "No mestrado eu comecei a pesquisar sobre essa coisa de inclusão, a minha 
pesquisa era sobre isso e eu vi que não tinha nada na área e comecei a me interessar por esse assunto" (Viviane).

Viviane relatou que foi em um dos cursos que fez que se encantou pelo cérebro humano, chegando até a fazer algumas aulas em uma faculdade de medicina:

Na APAE eu fiz um curso de psicomotricidade e me encantei pelo assunto e aí eu comecei a estudar por conta, aí eu fui fazer todos os cursos que eu conseguia naquela área, e ler também muita coisa. Então por causa da psicomotricidade eu acabei indo pra neurociência, comecei a estudar umas coisas de neuro, fazer umas aulas lá na Faculdade Paulista de Medicina, e eu realmente eu me encantei pela neurociência e hoje eu tô fazendo doutorado nessa área. Eu fiz dois anos de aula de psicologia, particular. Então assim, a neuro e a psicologia são dois alicerces muitos fortes pra mim. (Viviane)

Os conhecimentos dessas outras áreas que ajudaram a professora na sua trajetória foram de muita importância para a sua formação. Tanto a área da Educação ou da Educação Musical não são estritamente independentes. Volto a corroborar com a ideia Kraemer (2000) ao dizer que a Educação Musical depende de outras áreas. Para Viviane, o contato com a psicomotricidade foi fundamental na ponte com conhecimentos musicais.

Viviane se interessou pela inclusão e pela Educação Especial logo após entrar no Mestrado. Já no caso de Rafael foi um pouco diferente, o interesse pelo ensino de música para cegos veio antes do mestrado. Porém, foi lá que teve mais contato com a pesquisa sobre a musicografia Braile e a chance de contribuir para o campo da pesquisa com a sua dissertação “que é uma análise das particularidades da partitura em Braile pra auxiliar o ensino de pessoas cegas" (Rafael).

Viviane veio ter conhecimento sobre a precariedade de pesquisas quando entrou no mestrado, Rafael já tinha conhecimento desse fato antes mesmo de entrar no mestrado. O conhecimento sobre esse tema não deveria estar presente apenas na formação de pessoas que se interessam ou, por ventura, esbarram com a Educação Especial. A diversidade deve ser debate constante em graduações, afinal todos deveriam estar cientes que encontraremos inúmeros contextos e pessoas singulares durante toda a vida. 
Na história de Rafael e de Lisbeth há uma similaridade, pois, a professora também contou que seu interesse pela Educação Especial surgiu ainda no magistério. O mestrado veio ao encontro com a sua prática docente, em sua dissertação Lisbeth fala sobre um tema semelhante a esta presente pesquisa: a Formação e prática docente musical no processo de educação inclusiva de pessoas com necessidades especiais, sendo este o próprio título do trabalho. Nela a professora examina relações entre as práticas de alunos com necessidades especiais incluídas no ensino regular e a formação de professores de música em relação ao atendimento às necessidades dos alunos, por meio da observação de três professores de música atuantes em escolas particulares de educação básica em um município da Grande São Paulo.

Na pesquisa de Lisbeth, além de discursar sobre a formação de professores que atuam num contexto de inclusão, é possível notar que a mesma, do ano de 2006, ainda é uma das únicas no Brasil que abordam essa temática, juntamente com as pesquisas de Santos (2008), Machado (2012) e Viana (2015). Justifica-se assim que a área da pesquisa nesse tema desenvolveu-se de forma lenta.

Embora a formação dos entrevistados tenha ocorrido em épocas diferentes, com idades diferentes, a mesma sempre esteve atrelada com a atuação profissional. A necessidade de suas atuações, fizeram com que a busca por mais informações se fizesse imediata.

\section{SOBRE A ATUAÇÃO DOS ENTREVISTADOS}

Como já mencionado, Viviane teve sua primeira atuação na com o ensino de música para pessoas com deficiência decorrente da sua pesquisa de Mestrado que era sobre adaptações de instrumentos musicais para pessoas com deficiência. Segundo a professora, foi uma surpresa pois ela não esperava que, o que ela achava ser apenas uma pesquisa, iria leva-la à ter o contato direto com o ensino de pessoas com problemas psiquiátricos:

[...] alguém soube que eu, porque eu achei que ia ser só uma pesquisa e pronto, mas alguém soube que eu tava pesquisando sobre isso, um moço que fazia aula comigo, e aí me chamou pra dar aula em um lugar em São Paulo 
que eram com pessoas com problemas psiquiátricos e eu fui dar aula lá. Só que assim, eu não tinha noção do que eu tava fazendo entendeu. (Viviane)

Foi então no baque de não saber o que fazer e da necessidade de ensinar música para essas pessoas que levou Viviane a uma busca incansável por conhecimentos que a ajudariam com a sua didática.

A prática gera uma grande demanda para a formação. Primeiramente, se há leis como a 9.394 (BRASIL, 1996), que estabelece as diretrizes e bases da educação incluindo os alunos com necessidades especiais no ensino regular, e a própria 11.769 (BRASIL, 2008), que dispõe sobre a obrigatoriedade do ensino de música na educação básica, que estão em vigor a falta de demanda não é uma justificativa para a falta de cursos profissionalizantes. Viviane relatou que a AACD oferece cursos de capacitação na área da Educação Especial.

A professora relatou também que foi na prática onde mais aprendeu. Ainda durante o mestrado, ela foi à AACD em busca de estágio. Lá, no setor de musicoterapia, trabalhou por dois anos onde teve contato com diversas patologias, fazia aulas toda semana devido a diversidade das necessidades exigidas por cada setor:

Toda semana eu tinha aula lá porque lá é dividido por patologias, problemas neurológicos, problemas musculares, acidente e uma série de coisas, aí eu fui passando. Foi bom, eu pude acompanhar a fisioterapia, clínica médica, psicologia, fonoaudiologia, todas essas áreas, então eu fui meio que entrando nessa coisa da medicina, comecei a curtir muito. (Viviane)

A professora também relatou que, nos dezessete anos de atuação que tem, já trabalhou com quase todos os tipos de patologias, a única que nunca teve muito contato foi a cegueira:

Nesse primeiro lugar que eu trabalhei foi tudo junto, então foi onde eu tive um geral com todo mundo, depois eu fui trabalhar em coisas específicas, tem lugar que eu trabalhava só com síndrome de Down, trabalhei com surdos cinco anos, aí fui estudar libras pra poder falar com eles é, aí tive um trabalho com surdos muito legal, de cinco anos. Aí depois eu comecei me encantar mais pela questão da mente mesmo, problemas psiquiátricos, deficiências 
intelectuais era o que eu mais gostava, aí eu meio que me especializei nisso né, na deficiência mental. E de uns tempos pra cá, de uns seis sete anos pra cá, eu comecei a trabalhar mais com autismo, então assim meu doutorado foi com crianças autistas. Hoje em dia, talvez, o autismo esteja mais no meu foco, mas eu tenho experiência com tudo, mas a única deficiência que eu não tenho tanta experiência é com cegos, eu trabalhei com cegos mas assim dois ou três, mas foi muito por cima, então essa parte de música com Braile essas coisas eu sei como funciona, eu cheguei a fazer aula de Braile pra ter uma ideia de como escreve e tal mas não é a minha especialização entendeu?! (Viviane)

Na conversa que tivemos, ela afirmou que não é possível entender e saber lidar com as patologias numa totalidade. Até porque cada uma é singular e distinta. Ter contato com várias delas é fundamental para o crescimento profissional, mas também ter um foco faz com que você se concentre em desenvolver conhecimentos mais profundos sobre isso. Entretanto, corroboro com uma fala presente nas entrevistas sobre a consciência da existência dessa diversidade de especificidades que deve estar presente na mente e na formação de todos os seres humanos. Atualmente Viviane atua como docente efetiva na Universidade Federal de Pernambuco. Todos os entrevistados acentuaram a falta de pesquisas, materiais e cursos na área da educação musical como o primeiro obstáculo encontrado ao iniciarem no campo de trabalho na época, fato este que ainda pode ser considerado até o presente momento que esta pesquisa foi realizada.

Fazer com que as barreiras de falta de métodos práticos de ensino sistematizados não sejam sinônimo de impossibilidade de atuar são necessários para o processo de ensino-aprendizagem tanto de professores quanto de alunos. Silva (2007) traz em sua pesquisa uma situação similar com a de Rafael, pois a partir de exercícios e metodologias práticas presentes em livros e pesquisas sobre música a adaptação para diferentes contextos teve de ser realizada para que abrangesse as especificidades de cada aluno. Mas é importante que professores que estão atuando num contexto inclusivo, que também fazem adaptações de exercícios registrem essas atividades em forma de pesquisas, publicações, para contribuir 
com a construção de conhecimentos sobre a atuação e prática inclusiva em salas de aula.

Após aprender a musicografia braile por conta própria e devido a falta de cursos sobre o assunto, o próprio Rafael decidiu compartilhar o que tinha aprendido com quem tivesse interesse em aprender a musicografia braile, foi então que começou a ministrar cursos. Segundo ele, no começo era apenas para seus alunos do coral, mas depois tomou outras proporções e outros educadores, cegos ou não, vinham para o seu curso com a intenção de aprender. Rafael também trabalhou como voluntário no Centro Cultural Louis Braille de Campina por quatro anos. Segundo o professor, durante este período pode desenvolver suas atividades com o Braille de forma bem livre.

Atualmente Rafael tem voltado seus estudos para a Musicalização através do Método Dalcroze, que está cursando no Chile com professores credenciados pelo Conservatório Dalcroze da Suíça, em paralelo tem um grupo que compõe músicas infantis e atividades de musicalização, o Encantoré6. O professor também contou que tem planos de, após essa formação no Método Dalcroze, retornar para o tema do ensino para pessoas com deficiência visual com o suporte deste método, possivelmente depois se tornando tema de doutorado.

Lisbeth talvez seja a que mais se diferencia dos outros entrevistados quando falamos de atuação. Quando ainda estava na graduação, foi trabalhar como professora de Educação Infantil, lá teve contato com vários alunos com deficiência; Lisbeth contou que já atuou com todo tipo de deficiência, fosse na escola de música ou na escola regular. Concursada, trabalha há anos no cargo de professora de Educação Especial no município de São Bernardo do Campo, em São Paulo:

Quando eu comecei na escola especial eu comecei primeiro como professora de classe. Mas eu já tinha em paralelo em outra escola como professora de música, mas aí surgiu a oportunidade na escola especial a possibilidade de ficar como professora de arte, mas aí como eu tinha a formação em música, fazia sempre um trabalho voltado mais pro lado da música. (Lisbeth) 
A professora relatou ainda que o concurso para professor de Educação Especial na cidade é separado por deficiência, no caso dela o cargo é voltado para deficientes mentais. Lisbeth trabalha com alunos de inclusão desde 1998, e com o ensino de música há vinte e quatro anos, sendo entre os entrevistados a que tem mais tempo de experiência de atuação. Atualmente trabalha no ensino fundamental I como professora da sala de recursos, onde atende alunos de inclusão do município.

\section{CONCLUINDO}

Em meio a inúmeros temas que nos deparamos durante a nossa trajetória de conhecimentos, alguns nos chamam mais atenção do que outros. Por vezes, jamais imaginaríamos nos interessar por determinados temas e/ou talvez atuar em determinados contextos. O ensino de música na Educação Especial faz com que paremos para pensar que oportunizar a aprendizagem musical, saber respeitar a especificidades de todos os nossos alunos é um dos papéis fundamentais que temos enquanto educadores musicais.

Entender como foi a trajetória acadêmica e profissional de professores de música que atuam na educação especial foi o objetivo principal dessa pesquisa. Em alguns casos, como foi na trajetória de Viviane e Rafael, a formação veio devido a necessidade de atuar. Em outros o interesse pela formação veio antes mesmo da graduação, como foi o caso de Lisbeth. Independentemente de como tenha sido, é válido ressaltar em como, muitas vezes, a formação e a atuação de professores andam de mão dadas.

Conversar com professores de perfis tão diferentes foi esclarecedor em muitos pontos. Um deles foi perceber que a partir de seus interesses e necessidades de suas atuações, o profissionalismo superou as barreiras encontradas por eles no início de suas carreiras. Outro ponto que me chamou bastante atenção foi a força de vontade deles na busca por conhecimentos que o auxiliassem. Viviane e Rafael me disseram que não é porque o fato de não encontrarem, na época, pesquisas e cursos que precisavam que deixaram isso se tornar uma barreira inquebrável. Lisbeth, apesar de ter sua formação 
em outra área, teve a música como sua principal ferramenta de ensino, e mesmo tendo o cargo de professora de Artes sempre viu a necessidade de incluir a música em suas aulas.

Para esta pesquisa a internet teve papel fundamental para que a conversa com os professores fosse possível. Apesar da distância física foi possível estar próximo dos entrevistados mesmo que apenas virtualmente. Neste quesito, a internet contribui notavelmente com a facilidade e possibilidade de realizar pesquisas que, alguns anos atrás, seriam um pouco mais complicadas de se realizar devido aos meios de comunicação não serem tão presentes e acessíveis.

Ao concluir notei, baseado no relato dos entrevistados, que o campo da Educação Musical atualmente vem crescendo no âmbito de pesquisas sobre o tema abordado, porém a demanda da área necessita que esse número cresça cada dia mais. Pude notar também que os entrevistados disseram que conhecem pessoas que trabalham com o ensino de música para deficientes, mas que, não registram seus resultados em pesquisas ou publicações seja acadêmica ou não formal, como blogs entre outros, não é possível ter conhecimento de muitas coisas boas que podem e, provavelmente, devem estar acontecendo dentro das aulas de música que têm alunos de inclusão.

O debate sobre o tema deve estar cada vez mais presente dentro do meio acadêmico assim como a conscientização da importância de ampliar o número de pesquisas sobre o tema, devido a demanda atual da sociedade. 


\section{REFERÊNCIAS}

ALMEIDA, Maria Amelia. Formação do professor para a educação especial: história, legislação e competências. Centro de educação Cadernos, n. 24, 2004.

BRASIL. Lei 9.394 de 20 de dezembro de 1996. Estabelece as Diretrizes e Bases da Educação Nacional. Brasília. Disponível em: http://www.planalto.gov.br/ccivil 03/leis/19394.html. Acesso em: 03 out. 2018.

. Lei 11.769 de 18 de agosto de 2008. Altera a Lei n. 9394/96, para dispor sobre a obrigatoriedade do ensino de música na educação básica. Brasília: Presidência da República, 2008. Disponível em: http://www2.camara.leg.br/legin/fed/lei/2008/lei-11769-18agosto-2008-579455-publicacaooriginal-102349-pl.html. Acesso em: 03 out. 2018.

FERNANDES, J. N. Pesquisa em educação musical: situação no campo das dissertações e teses dos cursos de pós-graduação stricto sensu em Educação. Revista da ABEM, Porto Alegre, V. 5, 45-57, 2000

. Pesquisa em educação musical: situação no campo das dissertações e teses dos cursos de pós-graduação stricto sensu brasileiros. Revista da ABEM, Porto Alegre, V. 15, 11-26, 2006

A Pesquisa em Educação Musical no Brasil - Teses e Dissertações - Diversidade Temática, Teórica e Metodológica. Educação musical no Brasil. In: Oliveira, A. \& Cajazeira, R. (orgs.), Salvador, P\&A, 2007.

KRAEMER, Rudolf-Dieter. Dimensões e funções do conhecimento pedagógico-musical. Em Pauta: Revista do Programa de PósGraduação em Música da Universidade Federal do Rio Grande do Sul, Porto Alegre, v. 11, n. 16/17, p. 50-73, 2000. Disponível em: http://seer.ufrgs.br/index.php/EmPauta/article/viewFile/9378/5550. Acesso em: 03 out. 2018.

MACHADO, Dulcinéia. A Educação Especial na formação e na prática pedagógica do professor de música. Trabalho de Conclusão de Curso. Florianópolis: UDESC, 2012. Disponível em http://sistemabu. udesc.br/pergamumweb/vinculos/000000/000000000017/00001767. pdfAcesso em: 03 out. 2018. 
SANTOS, Claudia Eboli Corrêa dos. A Educação Musical Especial: Aspectos históricos, legais e metodológicos. Dissertação de Mestrado, UFRJ. Rio de Janeiro, 2008. Disponível em: http://www.unirio.br/ ppgm/arquivos/dissertacoes/claudia-eboli. Acesso em: 03 out. 2018.

SILVA, Crista Soares da. Educação Musical para Surdos: Uma experiência na Escola Municipal Rosa do Povo. Artigos da Meloteca. Rio de Janeiro, 2007. Disponível em: https://musicaeinclusao.files. wordpress.com/2013/06/mono-pre-textual-tinal.pdf. Acesso em: 03 out. 2018

SOARES, Lisbeth. Formação e prática docente musical no processo de Educação Inclusiva de Pessoas com Necessidades Especiais. Dissertação (Mestrado em Educação Especial), UFSCAR. São Carlos, 2006. Disponível em: https://repositorio.ufscar.br/bitstream/handle/ ufscar $/ 2954 /$ DissLS.pdf? sequence $=1 \&$ isAllowed $=y$. Acesso em: 03 out. 2018.

STAKE, Robert. Pesquisa Qualitativa: estudando como as coisas funcionam. Editora: Penso. Tradução: Karla Reis, 2011.

VIANA, Ana Célia de Lima. Uma proposta de capacitação na área da educação musical especial. Dissertação de Mestrado. São Carlos: UFSCar, 2015. Disponível em: https://repositorio.ufscar.br/handle/ ufscar/3194. Acesso em: 03 out. 2018.

WESTERMANN, Bruno. A autonomia do aluno de violão em um curso de licenciatura em música a distância: um estudo sobre os fatores de influência. Revista da ABEM, v. 20, n. 29, p. 78-87, 2012. 